\title{
A carteira escolar está "apta para o seu destino"? Argumentos e exigências sobre o mobiliário escolar em Exposições Universais
}

\author{
Gustavo Rugoni de Sousa ${ }^{1}$ \\ Ana Paula de Souza Kinchescki ${ }^{2}$ \\ Vera Lúcia Gaspar da Silva ${ }^{3}$
}

\section{RESUMO}

O mobiliário escolar é reconhecido como um dos símbolos da educação moderna e ocupou um lugar de destaque em projetos de escolarização da infância no ocidente, principalmente a partir da segunda metade do século XIX. Dentre os diferentes artefatos idealizados para atender exigências pedagógicas e higiênicas, selecionamos a carteira escolar como o fio condutor das análises desenvolvidas neste artigo por entendermos que, além do destaque recebido em impressos em circulação, ela foi considerada nesse período como um dos elementos essenciais para a (con)formação de práticas e condutas. Nessa direção, este trabalho tem como objetivo identificar, em discursos que circularam em Exposições Universais em diferentes formatos, elementos que caracterizavam a carteira escolar adequada para o desenvolvimento de práticas pedagógicas. Para tanto, são analisados relatórios de Exposições Universais, catálogos de indústrias e dicionários pedagógicos, os quais auxiliaram na identificação de argumentos que defendiam a construção de carteiras escolares que atendessem a um padrão de exigências veiculadas em eventos desse porte. Nessa empreitada foi possível observar um efeito de transbordamento de exigências difundidas nas Exposições Universais no que se refere a saberes e tecnologias empregados na construção de móveis escolares, assim como a

1 Doutor em Educação pela Universidade do Estado de Santa Catarina (UDESC). Professor Substituto na Universidade do Estado de Santa Catarina - UDESC, atuando na graduação. Integrante do Grupo de Pesquisa Objetos da Escola. E-mail: gustavorugoni@gmail.com

2 Mestra em Educação pela Universidade Estado de Santa Catarina (UDESC). Doutoranda em Educação no Programa de Pós-Graduação em Educação da Universidade do Estado de Santa Catarina (UDESC). Professora Substituta na UDESC, atuando na graduação. Integrante do Grupo de Pesquisa Objetos da Escola. E-mail: anapaulakin@gmail.com.

3 Doutora em Educação pela Universidade de São Paulo (USP). Pós-doutorado realizado na Universidade de São Paulo (USP). Professora titular da Universidade do Estado de Santa Catarina (UDESC), atuando na graduação e no Programa de Pós-Graduação em Educação (mestrado e doutorado). Integrante do Grupo de Pesquisa Objetos da Escola. Bolsista do Produtividade em Pesquisa, do CNPq. E-mail: vera.gaspar.udesc@gmail.com. 
elaboração de um conjunto de estratégias que visavam à adequação de escolas primárias de acordo com os modelos referenciados como ideais para a escolarização da infância.

Palavras-chave: Mobiliário escolar. Exposições Universais. Cultura material escolar.

\section{Is the school desk "fit for its destiny"? Arguments and requirements on school furniture in Universal Exhibitions}

\section{ABSTRACT}

School furniture is recognized as one of the symbols of modern education and has occupied a prominent place in childhood schooling projects in the West, mainly from the second half of the $19^{\text {th }}$ century. Among the different artifacts designed to meet pedagogical and hygienic requirements, we selected the school desk as the guiding thread of the analyses conducted in this article because we understand that, in addition to the prominence that it received in printed documents in circulation, it was considered in this period as one of the essential elements for the (con)formation of practices and conducts. In this sense, this work aims to identify, in discourses that circulated in Universal Exhibitions in different formats, elements that characterized the school desk fit for the development of pedagogical practices. For this purpose, reports of Universal Exhibitions, catalogs of industries and pedagogical dictionaries are analyzed, which helped in the identification of arguments that advocated the construction of school desks that met a standard of demands conveyed in such events. In this task, it was possible to observe an overflowing effect of demands disseminated in the Universal Exhibitions with regard to knowledge and technologies employed in the construction of school furniture, as well as the elaboration of a set of strategies aimed at the adequacy of primary schools in accordance with the models referred to as ideal for the schooling of childhood.

Keywords: School furniture. Universal Exhibitions. School material culture. 


\section{¿Es el pupitre escolar "adecuado para su destino"? Argumentos $y$ exigencias sobre el mobiliario escolar en Exposiciones Universales}

\section{RESUMEN}

El mobiliario escolar es reconocido como uno de los símbolos de la educación moderna y ha ocupado un lugar prominente en los proyectos de escolarización de la infancia en Occidente, principalmente desde la segunda mitad del siglo XIX. Entre los diferentes artefactos diseñados para satisfacer las exigencias pedagógicas e higiénicas, seleccionamos el pupitre escolar como el hilo conductor de los análisis desarrollados en este artículo porque se entiende que, además del énfasis recibido en impresos en circulación, se consideró en este período como uno de los elementos esenciales para la (con)formación de prácticas y conductas. En esta dirección, este artículo pretende identificar, en los discursos que circularon en Exposiciones Universales en diferentes formatos, elementos que caracterizaron el pupitre escolar adecuado para el desarrollo de prácticas pedagógicas. Para ello, se analizan informes de Exposiciones Universales, catálogos de industrias y diccionarios pedagógicos, los cuales ayudaron en la identificación de argumentos que abogaban por la construcción de pupitres escolares que atendieran un patrón de demandas transmitidas en tales eventos. En esta investigación fue posible observar un efecto desbordante de las demandas difundidas en las Exposiciones Universales con respecto a los conocimientos y tecnologías empleadas en la construcción de muebles escolares, así como la elaboración de un conjunto de estrategias dirigidas a la adecuación de las escuelas primarias de acuerdo con los modelos considerados ideales para la escolarización de la infancia.

Palabras clave: Mobiliario escolar. Exposiciones Universales. Cultura material escolar.

\section{Introdução}

Reconhecido como um dos símbolos da educação moderna, o mobiliário escolar passa a ocupar um lugar de destaque em projetos de escolarização da infância no ocidente, principalmente a partir da segunda metade do século XIX. Nesse período, os móveis idealizados para a escola primária são imaginados com base em argumentos e discursos que circu- 
laram cada vez com mais destaque em eventos internacionais, catálogos de indústrias, dicionários e outros formatos de impressos pedagógicos. No cerne desse imaginário, esses objetos são alçados como essenciais para a (con)formação de práticas e condutas e como componentes a serem considerados no que diz respeito ao provimento material escolar.

Pesquisas que envolvem a temática ${ }^{4}$ têm permitido identificar que o mobiliário escolar sofre, com o passar dos anos, alterações que não se restringem a características materiais, mas que estão relacionadas também a significados a ele atribuídos. No que se refere à definição do termo, observou-se que este pode designar conjuntos de diferentes artefatos, ora mais restritos, ora mais ampliados. No intuito de dar ao termo maior precisão, para a elaboração deste artigo optamos por realizar incursões em dicionários pedagógicos ${ }^{5}$ em busca, por meio dos verbetes, de indícios que nos permitissem compreender a constituição de sentidos e significados associados ao mobiliário escolar. Nesse movimento apurou-se que, de um entendimento que contemplava todos os artefatos presentes em uma sala de aula ${ }^{6}$, este conceito é ressignificado, passando a englobar apenas os elementos de uso comum e de "utilidade permanente", como, por exemplo, mesas, bancos, escrivaninhas, cabideiros, entre outros. Além das acepções localizadas em dicionários pedagógicos, a documentação consultada permitiu identificar a preocupação de autores e textos em circulação de destacar que os móveis presentes em uma sala de aula deveriam estar em condições consideradas adequadas para as práticas pedagógicas e de saúde pública, acompanhando ideias difundidas em grandes eventos como as Exposições Universais ${ }^{7}$.

4 Registramos aqui investimentos do Grupo de Pesquisa Objetos da Escola, com destaque para o trabalho de investigação que originou a tese de doutorado "A (re)invenção do mobiliário escolar: entre saberes pedagógicos, higienistas e econômicos (1851-1889)", de autoria de Gustavo Rugoni de Sousa, defendida em 2019 no PPGE da UDESC, disponível em: http:// sistemabu.udesc.br/pergamumweb/vinculos/000076/00007609.pdf.

5 As referências aqui utilizadas são a versão traduzida e ampliada por Camilo Castelo Branco do Dictionnaire Universel d'Éducation et Enseignement, organizado por Émile Mathieu Campagne, a qual foi publicada em Portugal no ano de 1886 (três volumes) com o título Diccionario Universal de Educação e Ensino; a edição do Dictionnaire de Pédagogie et d'Instruction Primaire, publicada em 1888, e a do Nouveau Dictionnaire de Pédagogie et d'Instruction Primaire de 1911, ambas organizadas por Ferdinand Buisson.

6 Incluem-se aqui os materiais de ensino como, por exemplo, globos terrestres, quadros parietais, relógios.

7 Émile Mathieu Campagne (1886), no verbete que trata sobre o mobiliário escolar, afirma que as adaptações higiênicas e pedagógicas realizadas nos móveis escolares eram fundamentais para que esses objetos pudessem ser considerados "aptos para os seus destinos", ou, em 
Observou-se a defesa de que os novos inventos deveriam afastar-se de características consideradas antipedagógicas e anti-higiênicas, ao passo que ganharam força recomendações para que se aproximassem de modelos apresentados em eventos internacionais, os quais eram legitimados como referenciais por meio de premiações e avaliações apresentadas em relatórios. Dentre os artefatos que compõem o mobiliário, selecionamos a carteira escolar como o fio condutor das análises que serão desenvolvidas neste artigo. Essa escolha se fundamenta no destaque que o referido artefato recebeu em diversas publicações do período oitocentista e na observação de que a idealização da carteira escolar está vinculada a movimentos que contribuíram para alterações e adequações de outros móveis escolares, tais quais armários-museus, mesas, escrivaninhas e quadros-negros.

Dessa forma, o presente trabalho possui como objetivo identificar em discursos que circularam em Exposições Universais, em diferentes formatos, elementos que caracterizavam a carteira escolar adequada para o desenvolvimento de práticas pedagógicas. Reconhece-se que os diferentes objetos contemplados pelo conceito de mobiliário escolar obedecem a prescrições específicas para a sua elaboração e podem possuir finalidades distintas com relação a seus usos. Contudo, advoga-se aqui que esses artefatos compartilham saberes pedagógicos e higiênicos, tomados como essenciais em seus processos de idealização e fabricação.

Estudos realizados no âmbito da História da Educação têm contribuído para adensar discussões acerca de diferentes projetos educativos constituídos ao longo do tempo e que possibilitaram o reconhecimento da escola como uma das instituições responsáveis pela aquisição e difusão de saberes, condutas e práticas. Um olhar mais atento a essas produções permite identificar diferentes dimensões que estão envolvidas no processo de consolidação da escola como um espaço legitimado socialmente para a escolarização da infância. Dentre caminhos possíveis para a compreensão das diversas realidades educativas, nossas pesquisas têm privilegiado o enfoque na materialidade escolar, investindo em uma perspectiva que busca problematizar relações em torno da idealização, fabricação e comercialização de objetos, bem como múltiplos sentidos e significados que podem assumir diante de prescrições estabelecidas e condições de uso/desuso.

outras palavras, que estivessem adequados e fossem eficientes para serem utilizados nas escolas. 
Nessa empreitada, temo-nos dedicado à elaboração de produções que possam colaborar com os debates e análises em torno da cultura material escolar, em particular aqueles que reconhecem a escola como um mercado que, a partir da segunda metade do século XIX, despertou o interesse de uma indústria fabril nascente, devido a uma significativa demanda por objetos construídos especificamente para atender exigências que vinham se constituindo nos âmbitos político-pedagógico, higiênico e econômico (RUGONI DE SOUSA, 2019). Para além da natureza física dos objetos e das práticas com eles desenvolvidas, tem sido possível avançar na compreensão de movimentos existentes entre a transnacionalização de ideias pedagógicas, os circuitos das Exposições Universais, a formação de uma mão de obra local especializada e a ascensão de uma indústria escolar.

A construção dessa narrativa tem sido alimentada pela pesquisa em arquivos e consultas em diferentes formatos de documentos tais como impressos pedagógicos, catálogos de indústrias e relatórios de Exposições Universais. Conforme já mencionado, os dados localizados e as análises tecidas nos têm permitido identificar o mobiliário escolar como um conjunto de artefatos que receberam grande destaque e que passaram a ser reconhecidos como símbolos de uma modernidade educativa que se anunciava nos Oitocentos. Os investimentos em analisar fontes relativas à segunda metade do século XIX estão relacionados ao entendimento de que nesse período emergem movimentos, discursos, argumentos e indicações provenientes de diferentes áreas, que, ao circularem em eventos internacionais, contribuíram para a legitimação de modelos considerados ideais para a escola primária.

Exposições universais: do trabalho íntimo das escolas para o progresso das indústrias

Os livros Exposições Universais: Espetáculos da Modernidade do Século XIX e As grandes festas didáticas: a educação brasileira e as exposições internacionais (1862-1922), escritos respectivamente por Sandra Jatahy Pesavento (1997) e Moysés Kuhlmann Júnior (2001), são produções referenciais e leituras indispensáveis para aqueles que têm o interesse de realizar investigações históricas acerca de questões que podem ser exploradas nas Exposições Universais. Tais obras trazem reflexões que possibilitam o entendimento de que essas feiras internacionais não se constituíram apenas como vitrines de novos inven- 
tos, mas foram, principalmente, difusoras de discursos, utopias e de um imaginário que tinha o comércio e a busca pelo progresso como alguns de seus pilares.

A organização desses eventos e a disposição de seus pavilhões e objetos tinham entre seus objetivos representar a grandiosidade de um novo tempo que se anunciava e almejava. As invenções e novas tecnologias apresentadas possibilitavam um contato com aquela que era considerada a vanguarda do conhecimento científico, além de contribuírem para a construção de uma cultura material moderna, sustentada em grande parte pela expansão comercial e pela padronização de modelos, ideias e produtos fabricados por uma indústria em ascensão, principalmente em países europeus e nos Estados Unidos da América.

No entanto, cabe ressaltar a provocação realizada por Sandra Jatahy Pesavento (1997), que traz à tona o encantamento produzido pelas Exposições Universais como um "canto de sereia", uma vez que esses eventos, por meio de propagandas da indústria que se constituía, veiculavam valores e ideias segundo desejos de uma classe burguesa em ascensão. Para a pesquisadora, as Exposições eram espaços em que se buscava seduzir os trabalhadores, identificando-os como um dos principais responsáveis pelo progresso ${ }^{8}$, mas mascarando as condições reais de acumulação e dominação da burguesia, constituindo, portanto, um instrumento de sedução social.

O século XIX foi, por excelência, um momento de transformação em múltipla escala. A população aumentara, as cidades cresceram e colocaram aos governantes toda uma sorte de exigências, desde a reordenação espacial, redesenhando as ambiências, até o cumprimento dos serviços públicos demandados pelo "viver em cidades". Produtos novos e máquinas desconhecidas atestavam que a ciência aplicada à tecnologia era capaz de tudo ou, pelo menos, quase tudo. $\mathrm{O}$ valor dominante era o do progresso, caro às elites que dele faziam o esteio de uma visão de mundo triunfante e otimista. (PESAVENTO, 1997, p. 29)

8 Para Eric Hobsbawm (2007) o progresso, entendido por muitos como inevitável, pode ser considerado uma palavra-chave dos Oitocentos. Segundo o autor, há vários aspectos que precisam ser considerados ao se pensar sobre o desenvolvimento capitalista, pois se por um lado o progresso promoveu avanços tecnológicos e desenvolvimento científico que contribuíram para a melhoria da qualidade de vida, por outro, foi construído ao custo da dizimação de populações e países. 
Em perspectiva semelhante, Moysés Kuhlmann Júnior (2001) observa que os "palcos da modernidade" foram espaços em que se privilegiou a representação de uma crença acrítica no progresso, na técnica e na ciência. Por ser considerada essencial à normatização e edificação controlada da sociedade ocidental moderna, debates em torno da educação passaram a ser organizados em exposições pedagógicas a partir de 1862, na Inglaterra9 ${ }^{9}$. Dessa forma, consideramos que mais do que possibilitar a visualização de novos inventos para as escolas, as Exposições, ao privilegiarem a circulação de saberes, foram fundamentais para a internacionalização de modelos considerados referência para sistemas de ensino de diferentes nações.

Vale lembrar que tais Exposições foram sediadas em diferentes países ${ }^{10}$, tendo sido tema de matérias e artigos publicados em periódicos, impressos educacionais, dicionários pedagógicos e em catálogos de fábricas que circularam desde a segunda metade do século XIX, o que indica sua força e impacto tanto na difusão de ideias quanto na composição de discursos sobre a escolarização. Análises de documentos deste tipo têm permitido identificar que mensagens difundidas nos"palcos da modernidade" ressoaram em muitos suportes e em diferentes locais e que, para participar do "concerto das nações", muitos empenharam-se em enviar comissões com o objetivo de não apenas apresentar o que havia de melhor em seus países, mas também de importar modelos, ideias e técnicas para a modernização da sociedade.

A dimensão desses eventos pode ser observada em páginas do Diccionario Universal de Educação e Ensino: útil à mocidade de ambos os sexos, às mães de família, aos professores, aos directores e directoras de collegios e aos alumnos que se preparam para exame, escrito por Émile Mathieu Campagne (1886). Um dos verbetes presentes no documento intitula-se Exposições escolares, as quais eram realizadas no interior

9 O Relatório da Primeira Exposição Pedagógica, realizada no Rio de Janeiro em 1884, indica que 180 expositores, provenientes da França, Inglaterra, Saxônia, Baviera, Wurtemberg, Áustria, Bélgica, Suíça, Rússia, Dinamarca, Suécia, Noruega, Itália e Portugal, participaram da exposição que ocorreu na Inglaterra.

10 Em sua tese de doutorado, Gustavo Rugoni de Sousa (2019), com base nos trabalhos de Moysés Kuhlmann Júnior (2001) e Vera Lucia Gaspar da Silva \& Gizele de Souza (2018), além de outras fontes bibliográficas e documentos, apresenta um quadro (p. 114) com exposições internacionais que ocorreram entre os anos de 1851 e 1922. A partir de seus estudos, identifica-se que no referido período ocorreram, pelo menos, 63 eventos sediados em 21 países. No entanto, o autor ressalta que nem todas essas exposições tiveram a mesma repercussão na sociedade e que, portanto, é preciso considerar o local, o investimento e a divulgação envolvida na realização de cada uma delas. 
das Exposições Universais e tinham como objetivo, de acordo com seu autor, contribuir para o "aperfeiçoamento do ensino" por meio da apresentação de dados, estatísticas, relatórios, jornais escolares, livros, cartas, planos de estudos, atividades, objetos escolares, entre outros. Conforme destaca, diante da dificuldade de se apresentarem questões pedagógicas que dizem respeito à rotina escolar - como a relação estabelecida entre mestres e discípulos -, a apresentação das materialidades seria algo positivo nesses eventos, pois com os artefatos outros elementos que "se relacionam com a instrucção e a educação d'um povo"11 poderiam ser observados.

Do mesmo modo que, com o fim de concorrer para o desenvolvimento das industrias, se promovem exposições onde se patenteia ao publico os progressos que essas industrias têm realizado, assim tambem se tem pretendido aproveitar para o aperfeiçoamento do ensino a organisação de exposições escolares, especialmente destinadas a mostrar a organisação e resultados colhidos nas diversas escólas.

É, porém, claro que o problema é n'este caso extremamente complicado, porque não basta, como sucede com a arte e a industria, a representação material. Se se tratasse apenas de representar a escóla, no sentido concreto da palavra, o edifício, a mobília, o material d'ensino, mesmo até os livros, a cousa seria fácil; [...]

Todavia, se é impossivel exigir de uma exposição escolar a revelação do trabalho intimo da escola, ella póde ao menos mostrar os instrumentos e os órgãos do ensino, e indicar, até certo ponto, os resultados obtidos, o que já é extremamente interessante, [...]. (CAMPAGNE, 1886a, p. 1010).

A relação das Exposições com o desenvolvimento das indústrias é outro elemento que chama a atenção. Não por acaso, esses eventos foram reconhecidos como grandes feiras industriais devido à significativa presença de inventos e de ritos de classificação a partir de critérios previamente estabelecidos. Além da exposição dos artefatos escolares, a seleção, o julgamento e os prêmios atribuídos àqueles que seguiam as prescrições pedagógicas, médicas e higiênicas em voga contribuíram para a formação de modelos referenciais para a escolarização da infância. Como pode ser identificado em catálogos e relatórios de Exposições

11 Optamos por manter a ortografia dos documentos de origem utilizados neste artigo. 
Universais, essas distinções foram utilizadas como estratégias por parte de fábricas, no sentido de certificarem seus produtos em um patamar de excelência internacional. A Figura 1, a seguir, reproduz a capa de dois dos catálogos analisados, pertencentes a uma fábrica inglesa e outra francesa, ambas especializadas na produção de móveis e utensílios escolares. Como é possível observar, há um destaque para o registro de medalhas recebidas em exposições nacionais e internacionais ${ }^{12}$.

Figura 1 - Capas de catálogos com representações de prêmios recebidos
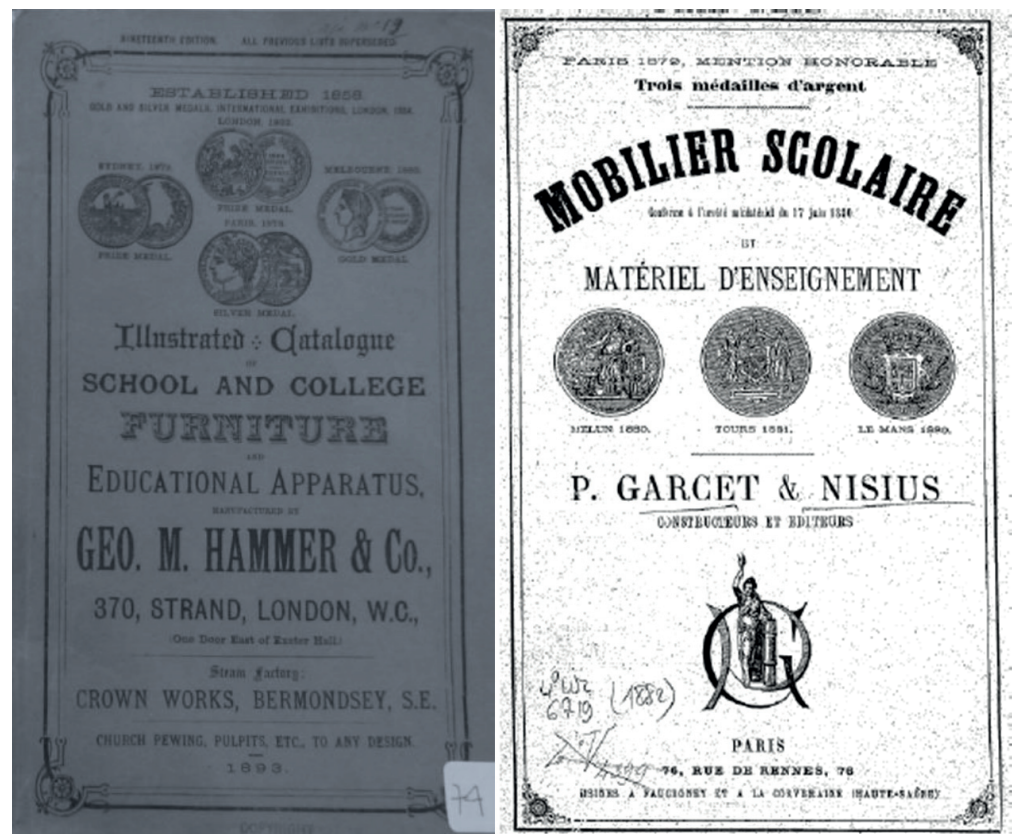

Fonte: Geo. M. Hammer (1893); P. Garcet e Nisius (1882).

Com a expansão industrial, a promulgação de leis que regulamentaram a obrigatoriedade escolar e o fortalecimento de um modelo educacional que pressupunha o uso de diferentes artefatos, a partir da segunda metade do século XIX ocorreu um aumento significativo na

12 Ao analisar os catálogos elaborados já na primeira metade do século XX pela fábrica situada no sul do Brasil e conhecida popularmente como "Móveis CIMO", Gustavo Rugoni de Sousa (2015) também identificou o recurso da menção às premiações como forma de valorização e destaque dos produtos ofertados. Este é um dos indícios que demonstram a permanência dessa estratégia e da importância das Exposições Universais como um espaço utilizado pelas fábricas como certificador de qualidade. 
produção e circulação de objetos idealizados especialmente para atender novas exigências escolares. A formação de professores e as práticas pedagógicas deveriam, nesse contexto, pautar-se em materialidades que colaborassem para que resultados satisfatórios fossem alcançados. Nessa direção, o mobiliário escolar foi considerado um dos elementos centrais nesse projeto e, em conjunto com outras tecnologias, como materiais visuais, sonoros e táteis para o ensino, instrumentos, suportes e acessórios de escrita, deveria estar ancorado em pressupostos higiênicos e em uma racionalidade pedagógica que visava à organização do espaço da sala de aula, dos corpos e das ações das crianças e de seus professores.

\title{
"A carteira deve se adaptar à criança e não ao contrário"
}

Para refletir sobre as Exposições Universais aqui compreendidas como espaços singulares para a circulação e difusão de ideias, técnicas e saberes, recorremos a Relatórios sobre a Instrução Primária apresentados em diferentes edições desse evento. Um dos documentos analisados faz referência a carteiras escolares divulgadas na Exposição Universal realizada no ano de 1873, em Viena, Áustria. Escrito por Ferdinand Buisson (1875), esse relatório destaca a importância das Exposições Universais para o aprendizado dos franceses no que diz respeito a novas invenções e metodologias de ensino. Sua intenção com a elaboração desse texto, conforme aponta no prefácio, não era realizar comparações entre os artefatos produzidos e utilizados nas escolas francesas e em outras nações, mas importar para seus respectivos países o que estava sendo exposto, por julgar que poderia contribuir com o desenvolvimento do ensino primário em seu país.

\begin{abstract}
A Exposição de Viena ofereceu, para o estudar, um conjunto bastante rico de documentos e exemplares, alguns dos quais elaborados muito recentemente. Ao examiná-los, pôde-se acompanhar quase de ano a ano as melhorias gradualmente introduzidas no mobiliário escolar em todo lugar em que houve esforço para aperfeiçoá-lo (BUISSON, 1875, p. 51) ${ }^{13}$.
\end{abstract}

13 Tradução livre do original: "L'exposition de Vienne offrait, pour l'étudier, un ensemble assez riche de documents et de spécimens, dont quelques-uns étaient tout récents. En les examinant, on pouvait suivre presque d'année en année les améliorations graduellement introduites dans le mobilier scolaire partout où l'on s'est attaché à le perfectionner." (BUISSON, 1875, p. 51) 
Ainda segundo o autor, o destaque para um mobiliário escolar produzido a partir de exigências anunciadas como modernas só passou a ocorrer a partir da Exposição Universal realizada no ano de 1867, em Paris, com a divulgação de carteiras escolares fabricadas em Illinois, Estados Unidos da América. De suas análises, depreende-se que a presença de exemplares dos móveis estadunidenses foi essencial para o aprendizado de novas tecnologias na área, pois apenas a leitura de documentos publicados no período não permitia conhecer, com exatidão, as soluções adotadas.

No Dicionário elaborado por Campagne (1886a, p. 1011) o verbete Exposições escolares também apresenta esses eventos como importantes para "fornecer uteis lições" para estudantes e mestres. Segundo o conteúdo de tal verbete, a Exposição realizada no ano de 1867 auxiliou a ampliar a divulgação de ideias pedagógicas, uma vez que contou com mais de 600 expositores nas seções relativas ao ensino popular. Já para a composição do verbete Mobilia escolar, uma das referências utilizadas é o estudo desenvolvido por Ferdinand Buisson a partir das mobílias apresentadas em Viena, no qual destaca "[...] os princípios que devem servir de guia para a escolha de uma boa mobília, na certeza de que uma aula bem arranjada, na qual a criança entre com um sentimento de prazer mesclado de respeito, dispõe-a e obriga-a até moralmente á aplicação e ao trabalho" (CAMPAGNE, 1886b, p. 843). No conteúdo do verbete identifica-se que a maior preocupação expressa por Émile Mathieu Campagne (1886b) relaciona-se a questões pedagógicas e à higiene. Apesar de serem classificadas por ele como componentes fundamentais para a escolarização da infância, considera que foi um assunto por muito tempo deixado de lado entre as preocupações de médicos e educadores.

A necessidade de adequar o mobiliário escolar a preceitos higiênicos também aparece em outras produções ${ }^{14}$ que circularam nos anos finais do século XIX e que, em diferentes países, apontavam a necessidade de realizar intervenções nos artefatos para que fosse possível o desenvolvimento de uma cultura escolar saudável. A leitura desses documentos permite identificar que esse era um dos desafios enfrentados no período e que os autores, com vistas a superá-los, apresentaram

14 Destacam-se aqui os seguintes trabalhos: Hygiène Scolaire: Influence de L'école sur la Santé des Enfants (A. Riant, 1874, Paris - França), Hygienic Requirements of School Furniture (G. A. Bodrick, 1892, Nova lorque - EUA), Higiene Escolar en sus relaciones con la miopia (Sebastián B. Rodriguez, 1891, Montevideo - Uruguai) e Manual das Escolas Elementares d'Ensino Mutuo (M. Sarazin, 1854, Bahia - Brasil). 
estratégias para a construção de materialidades e de um espaço que colaborasse para a saúde e a educação das crianças.

Cabe lembrar que o tema da higiene escolar tem sido contemplado em investigações desenvolvidas por pesquisadores da história da educação. Apoiamo-nos aqui em estudos de Heloisa Helena Pimenta Rocha, Antonio Viñao Frago e Aida Terrón Bañuelos, os quais indicam o século XIX como um período no qual circulou um vasto conjunto de publicações que contribuiu para a definição de novas propostas teórico-práticas e intervenções a partir da inserção das crianças no espaço escolar. A partir de seus estudos, identifica-se que com a expansão urbana e a proliferação de doenças, foi necessária a elaboração de um conjunto de estratégias por parte do Estado para garantir a saúde da população. Nesse processo, a escola passa a ocupar um espaço importante e a conquistar o reconhecimento de autoridades do ensino como a instituição ideal para a difusão de entendimentos e ações voltadas para o cuidado com o corpo, um dos elementos essenciais para o progresso social.

A confluência entre medicina, higiene e escola era inevitável. Por um lado, a escola surgia como o espaço social em que uma atenção médico-higiênica na infância podia ser controlada e realizada; especialmente, sobre a infância fraca, anormal ou atrasada. Por outro lado, através da escola, as famílias e os pais podiam ser alcançados. A medicalização da infância andou de mãos dadas com a sua escolaridade. E esta última com a higienização da escola. Com sua consideração como espaço privilegiado tanto para inculcar princípios e adquirir hábitos higiênicos, quanto para a realização de atividades (cantinas, duchas e banhos, acampamentos escolares, excursões, ginástica e exercícios corporais, etc.) que contribuíssem para melhorar a sua saúde (VIÑAO FRAGO, 2010, p. 186) ${ }^{15}$.

Seguindo os movimentos higienistas, um conjunto de remodelações e intervenções na materialidade escolar passa a ser reivindicado

15 Tradução livre do original: "La confluencia entre medicina, higiene y escuela era inevitable. Por un lado, la escuela aparecía como el espacio social en el que podía controlarse y llevarse a cabo una atención médico-higiénica sobre la infancia; en especial, sobre la infancia débil, anormal o retrasada. Por otro, a través de la escuela podía llegarse a las familias, a los padres. La medicalización de la infancia se daba la mano con su escolarización. Y esta última con la higienización de la escuela. Con su consideración como un espacio privilegiado tanto para la inculcación de principios y la adquisición de hábitos higiénicos, como para la realización de actividades (cantinas, duchas y baños, colonias escolares, excursiones, gimnasia y ejercicios corporales, etc.) que contribuyeran a mejorar su salud." (VIÑAO FRAGO, 2010, p. 186) 
nesse período com o objetivo de preparar espaços de modo que se tornassem saudáveis para receber as crianças e os professores. Essas reivindicações ganham força sustentadas, em grande parte, em estudos do campo médico que apontavam relações entre objetos considerados inadequados e insalubres com o aparecimento de desvios posturais, doenças oculares e respiratórias. O Relatório escrito por Ferdinand Buisson nos permite perceber a força dessas discussões ao avaliar as mobílias apresentadas na Exposição Universal de Viena, em 1873. Nesse documento é possível localizar, além dos pareceres de Buisson, um conjunto de imagens, quadros e esquemas que visavam a sistematizar informações sobre os diferentes exemplares, destacando as tecnologias e soluções implementadas por fábricas moveleiras que tinham como objetivo convencer as autoridades de ensino de que seus produtos estavam aptos para equipar as escolas e atender suas necessidades.

Entre os objetos que aparecem nas páginas escritas por Buisson, a carteira tem grande destaque sendo, segundo as palavras do autor, tornando-se o foco de atenção dos educadores no evento, por ser um artefato de uso direto das crianças, que interferia na implementação da pedagogia moderna e na prevenção de doenças. Dessa forma, as análises desenvolvidas a partir da leitura desse relatório permitiram observar a recorrência de alguns princípios comuns na idealização e fabricação das carteiras apresentadas na Exposição de 1873. Para serem consideradas modernas e conquistarem possíveis consumidores, ao idealizarem seus inventos os produtores deveriam seguir uma espécie de padrão de exigências que estava se consolidando no período e que era reforçado pelas Exposições Universais, bem como oferecer esses inventos modernos a um custo que fosse acessível a diferentes nações (RUGONI DE SOUSA, 2019). O Quadro 1 apresenta dois princípios médicos destacados por Buisson como essenciais para a elaboração de uma carteira escolar higiênica:

Quadro 1 - Princípios médicos comuns às carteiras escolares apresentadas na Exposição Universal de Viena (1873)

\begin{tabular}{|l|l|}
\hline $\mathbf{1 0}^{\circ}$ & $\begin{array}{l}\text { Estando a criança completamente sentada com os pés colocados no chão, } \\
\text { as pernas precisam formar com as coxas um ângulo reto, e o mesmo com } \\
\text { as coxas e o tronco. }\end{array}$ \\
\hline $\mathbf{2 0}^{\circ}$ & $\begin{array}{l}\text { A criança, mantendo a posição dos membros inferiores, deve poder } \\
\text { escrever sem assumir uma posição que atinja a parte superior do corpo, } \\
\text { isto é, não precisa se curvar sobre o papel ou tenha que elevar o ombro } \\
\text { para alcançar a mesa. }\end{array}$ \\
\hline
\end{tabular}

Fonte: Gustavo Rugoni de Sousa (2019, p. 129) com base em Ferdinand Buisson (1875, p. 56). 
Em nossas pesquisas, também localizamos uma obra publicada em Nova lorque, Estados Unidos, no ano de 1892, escrita por G. A. Bodrick e intitulada de Exigências higiênicas para o mobiliário escolar. A leitura da obra permite reforçar o entendimento de que ideias semelhantes sobre a adequação do mobiliário escolar circularam em diferentes países. Em foco, a higiene novamente aparece anunciada como um dos requisitos necessários para a adequação do mobiliário aos preceitos modernos de ensino. Para o autor, a revisão da materialidade escolar para evitar problemas respiratórios, miopia, cifose e curvatura cervicais, por exemplo, justificavam-se pela ideia de que a infância seria o momento ideal para a correção e incorporação de condutas e práticas consideradas saudáveis.

Além da preocupação com a saúde, ao longo da obra observa-se a recorrência de um discurso que vinculava materialidade, higiene e aspectos pedagógicos: a carteira escolar adaptada não apenas garantiria a saúde dos corpos, como também privilegiaria uma melhor atenção e obediência aos professores, entendidos como fundamentais para a fiscalização da execução das tarefas e comportamentos esperados. Em seus argumentos, Bodrick elenca quatro princípios que deveriam ser considerados ao se idealizarem e construírem móveis, na direção de garantir sua adequação e conforto:

1. Que todos os alunos, sejam os velhos ou jovens, devem ter uma mesa e um assento;

2. Que ambos sejam fabricados de maneira que favoreçam o maior conforto e estejam adaptados da meIhor forma possível;

3. Que os assentos e mesas sejam dispostos de modo que permitam que cada aluno se desloque para frente e para trás sem perturbar os outros. A esses pode ser acrescentado;

4. Que os assentos e mesas sejam fabricados com os materiais mais firmes e sólidos disponíveis, para que possam durar o maior tempo possível, contribuindo assim para economizar recursos (BODRICK, 1892, p. $10-11)^{16}$.

16 Tradução livre do original: "1. That every pupil, whether old or young, should have a desk as well as a seat; 2. That both should be made as comfortable and as well adapted to their object as possible; 3 . That the seats and desks should be so arranged as to permit each pupil to pass to and fro from his own, without disturbing any other in so doing. To these may be added; 4 . That the more neatly and substantially the seats and desks are made at first, the longer they will last, and the greater will be the saving to the school section in the end." 
A preocupação com requisitos defendidos por higienistas, bem como a utilização de slogans que pudessem destacar sentidos que estavam sendo construídos em torno dos novos inventos, ficam evidentes em diversas fontes analisadas. O lema a carteira deve se adaptar a criança e não ao contrário não aparece apenas no Relatório da Exposição Universal de Viena, escrito por Ferdinand Buisson, mas também em catálogos e outras publicações que constantemente buscavam vincular os inventos a exigências higienistas e pedagógicas. Nessa direção, dissemina-se em diferentes documentos e lugares a defesa da aquisição de carteiras com ajustes de altura ou de exemplares com diferentes tamanhos, permitindo que crianças de todas as estaturas fossem contempladas. A possibilidade de se realizar ajustes nas alturas das mesas, bancos, bem como na posição do encosto era um dos requisitos para que um modelo de carteira escolar fosse agraciado com uma premiação nas Exposições.

Quadro 2 - Móveis escolares premiados na Exposição Universal de Viena (1873)

\begin{tabular}{|c|c|c|}
\hline Instituições & Objetos Expostos & Premiações \\
\hline $\begin{array}{l}\text { Bahse e Haende, Chemnitz, } \\
\text { Saxônia. }\end{array}$ & Bancos escolares (Kunze) & Medalha do Progresso \\
\hline $\begin{array}{l}\text { Joseph Kaiser, professor de } \\
\text { Munique, Alemanha. }\end{array}$ & Bancos escolares (Kaiser) & Diploma de Mérito \\
\hline Joseph Ross, Boston, EUA. & $\begin{array}{l}\text { Melhorias de móveis } \\
\text { escolares (Ross - Boston) }\end{array}$ & Medalha de Mérito \\
\hline $\begin{array}{l}\text { Sociedade Nacional para o } \\
\text { mobiliário das escolas de } \\
\text { Nova lorque, EUA. }\end{array}$ & Carteira escolar & Medalha de Mérito \\
\hline Shattuck, Boston, EUA. & Carteira escolar & Diploma de Mérito \\
\hline Nichols, Boston, EUA. & Carteira escolar & Diploma de Mérito \\
\hline Bapterosses, Paris, França. & $\begin{array}{l}\text { Bancos escolares } \\
\text { (Bapterosses) }\end{array}$ & Diploma de Mérito \\
\hline
\end{tabular}

Fonte: Elaborado por Gustavo Rugoni de Sousa (2019, p. 119) com base em Buisson (1875, p. 94).

Conforme é possível visualizar, o Quadro 2 traz indicações de móveis premiados na Exposição realizada em Viena, no ano de 1873, e do destaque e visibilidade que o banco e a carteira escolar receberam

(BODRICK, 1892, pp. 10-11) 
nas preocupações e no provimento material da escola do período. A partir desses indícios, procuramos localizar mais informações que pudessem ajudar a compreender a idealização e fabricação dos exemplares exaltados como referências. Nesse processo não foi possível localizar imagens de todas as sete carteiras mencionadas acima, porém, o próprio relatório de Buisson, cotejado com catálogos de fábricas moveleiras, permitiu analisarmos com maior precisão os modelos Kunze ${ }^{17}, K^{\prime i-}$ ser, Shattuck, Ross ${ }^{18}$ e Bapterosses. As imagens das carteiras localizadas seguem no Quadro 3.

Diversas tecnologias aparecem associadas às carteiras premiadas na Exposição Universal de Viena. As análises dos exemplares apresentados no Quadro 3 permitem identificar que, embora possuam designs diferentes, há atributos semelhantes em todos os artefatos premiados. Entre as características mais enfatizadas, identificamos soluções tecnológicas que dizem respeito ao cuidado com o ajuste na altura e na distância considerada correta entre o banco e a mesa, a atenção aos elementos estéticos dos exemplares, a inclinação da mesa para facilitar a escrita e a leitura, além da utilização da madeira como matéria-prima principal. No processo de apropriação de ideias legitimadas nas Exposições, é possível observar que, ao mesmo tempo em que as fábricas buscavam atender exigências propagadas em diferentes documentos, leis e manuais pedagógicos, também produziram soluções e debates que foram incorporados e passaram a ser defendidos por educadores.

No intuito de sistematizar os atributos gerais dos exemplares contemplados com diplomas e medalhas, organizamos o Quadro 4, que detalha as principais características, nacionalidades das fábricas, indícios de locais em que os exemplares foram adquiridos para serem utilizados em escolas e a principal matéria-prima empregada em sua fabricação.

17 Carlos Manique da Silva, em artigo publicado em 2019, constata que o modelo Kunze destacado na Exposição Universal de Viena foi apropriado em diferentes países e que suas "imitações" podem ser identificadas em Portugal, pois a Direção Geral de Instrução Publica, no ano de 1877, indicou a utilização de modelos de carteiras escolares que tinham o sistema Kunze como referência.

18 Diferentemente dos outros modelos, a premiação recebida por Joseph Ross deveu-se aos aperfeiçoamentos realizados em um conjunto de móveis escolares que a fábrica produziu. No entanto, apresentamos no Quadro 3 a imagem que está disponível no Relatório elaborado por Buisson (1875). Em nossas pesquisas localizamos um dos catálogos da fábrica, publicado em Boston no ano anterior à Exposição de Viena, e constatamos um conjunto significativo de móveis escolares disponíveis para a comercialização. Além das carteiras escolares, constam neste catálogo suportes para desenho, bancos, tinteiros, ponteiras, escrivaninhas de professores, suportes para mapas, cadeiras e armários-museus. 
Quadro 3 - Imagens das carteiras premiadas na Exposição Universal de 1873

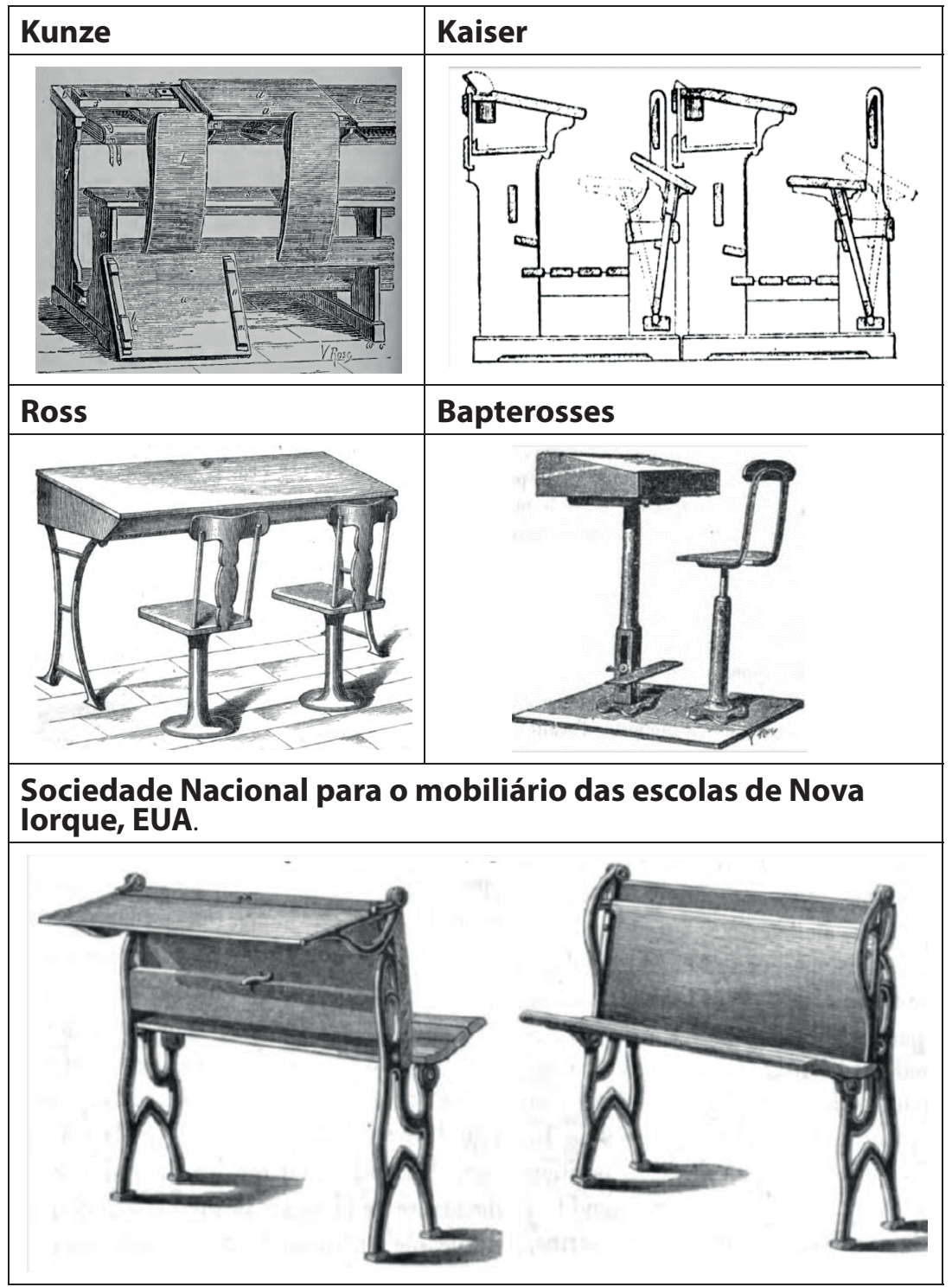

Fonte: Riant (1874) e Buisson (1875). Elaborado pelos autores.

Um olhar atento às características ressaltadas, tanto nas imagens, quanto em avaliações realizadas por Buisson e Riant, permite identificar que os modelos dispostos no Quadro 4 contavam, no mínimo, com uma 
tecnologia que os diferenciavam dos demais (em itálico). Como já foi apontado, as fábricas vinham aplicando seus conhecimentos na construção de novos mecanismos que auxiliassem a destacar seus inventos como singulares em comparação com a grande oferta de produtos escolares realizada por seus concorrentes. Ao articular as tecnologias com as premiações recebidas na Exposição de Viena, é possível identificar que a boa recepção do júri e as apreciações positivas, de certa forma, impulsionaram as fábricas na corrida capitalista pelo progresso.

No Quadro 4 é possível observar que todos os modelos premiados possuem tecnologias como engrenagens e parafusos que possibilitavam movimento, além de design com curvas em assentos e encostos para melhorar o conforto. Ao destacarem as "partes móveis" como um diferencial nas carteiras, Buisson e Riant indicam as fábricas estadunidenses como pioneiras na produção das tecnologias necessárias para a sua produção. Nos relatórios das exposições de Viena e da Filadélfia, realizadas em 1873 e 1876, respectivamente, Ferdinand Buisson insere imagens de modelos de carteiras Andrews, Stevens e Bancroft ${ }^{19}$ (Quadro 5), que, mesmo sem receberem premiações, ganharam destaque em seus pareceres em virtude de características como cavidades para tinteiro, assento dobrável, gavetas e simplicidade na construção.

Apesar de mais sucinto com relação ao mobiliário escolar que o relatório da Exposição de Viena (1873), o parecer do evento ocorrido na Filadélfia (1876) trata também de outras peças do mobiliário escolar. Nesse documento, para além das carteiras, Buisson discorre sobre mesas para uso dos professores e diferenças nos modos de atuação e na conformação material de salas de aula francesas e estadunidenses. Embora o autor apresente múltiplos modos de operacionalizar a escola primária, seus argumentos permitem identificar uma preocupação constante com a disseminação de condutas e hábitos saudáveis por meio de objetos considerados adequados. A defesa de um ensino que satisfizesse preceitos morais, por sua vez, também ocupava lugar em debates promovidos por representantes dos diferentes países que frequentavam e expunham seus inventos nas Exposições Universais, configurando-se como elementos que devem ser observados ao se analisarem configurações e projetos em torno da escolarização de uma infância almejada no período oitocentista.

19 Mesmo sem inserção de imagens, os modelos Slaymaker e Williams também são referenciados por Buisson no relatório da Exposição Universal de Viena. 
Quadro 4 - Carteiras escolares premiadas e suas características principais

\begin{tabular}{|c|c|c|c|}
\hline Modelo & Características & $\begin{array}{l}\text { Locais de } \\
\text { produção e/ou } \\
\text { em que foram } \\
\text { utilizadas }\end{array}$ & $\begin{array}{l}\text { Matéria- } \\
\text { prima } \\
\text { principal }\end{array}$ \\
\hline Kunze & $\begin{array}{l}\text { Deslizamento da base superior em } \\
\text { direção ao aluno; } \\
\text { Distância adequada entre banco } \\
\text { e mesa; } \\
\text { Tamanhos variados; } \\
\text { Baixo preço; } \\
\text { Construção simples; } \\
\text { Assento com curvatura confortável; } \\
\text { Apoio para os pés; } \\
\text { Apoio para guardar materiais. }\end{array}$ & $\begin{array}{l}\text { Local de produção: } \\
\text { Áustria, Hungria e } \\
\text { Alemanha }\end{array}$ & Madeira \\
\hline Kaiser & $\begin{array}{l}\text { Deslizamento do banco em direção } \\
\text { ao aluno; } \\
\text { Mesa e encosto fixos; } \\
\text { Grampos e tecidos evitam a } \\
\text { produção de ruídos ao movimentar } \\
\text { o banco; } \\
\text { Apoio para os pés com altura } \\
\text { regulável. }\end{array}$ & - & Madeira \\
\hline Bapterosses & $\begin{array}{l}\text { Carteira individual; } \\
\text { Mesa fixa; } \\
\text { Banco redondo, em haste de ferro } \\
\text { fixa em base de madeira; } \\
\text { Ajuste de altura do banco pode ser } \\
\text { interrompido a qualquer momento; } \\
\text { Pequeno apoio para guardar } \\
\text { materiais; } \\
\text { Apoio para os pés muito pequeno } \\
\text { (desvantagem). }\end{array}$ & - & $\begin{array}{l}\text { Madeira muito } \\
\text { simples }\end{array}$ \\
\hline $\begin{array}{l}\text { Sociedade } \\
\text { Nacional }\end{array}$ & $\begin{array}{l}\text { Carteira individual; } \\
\text { Banco dobrável; } \\
\text { Não produz ruídos ao movimentar } \\
\text { o banco; } \\
\text { Apoio para guardar materiais. }\end{array}$ & $\begin{array}{l}\text { Escolas rurais dos } \\
\text { Estados Unidos da } \\
\text { América }\end{array}$ & $\begin{array}{l}\text { Ferro fundido } \\
\text { e madeira }\end{array}$ \\
\hline Ross & $\begin{array}{l}\text { Diferentes tamanhos; } \\
\text { Construção simples; } \\
\text { Algumas mesas podem ser } \\
\text { erguidas; } \\
\text { Mesa inclinada para facilitar escrita } \\
\text { e leitura; } \\
\text { Considerado por Buisson muito } \\
\text { caro para ser usado nas escolas } \\
\text { francesas. }\end{array}$ & - & $\begin{array}{l}\text { Ferro fundido } \\
\text { e madeira }\end{array}$ \\
\hline
\end{tabular}

Fonte: BUISSON (1875) Elaborado pelos autores. 
Quadro 5 - Modelos destacados por Buisson

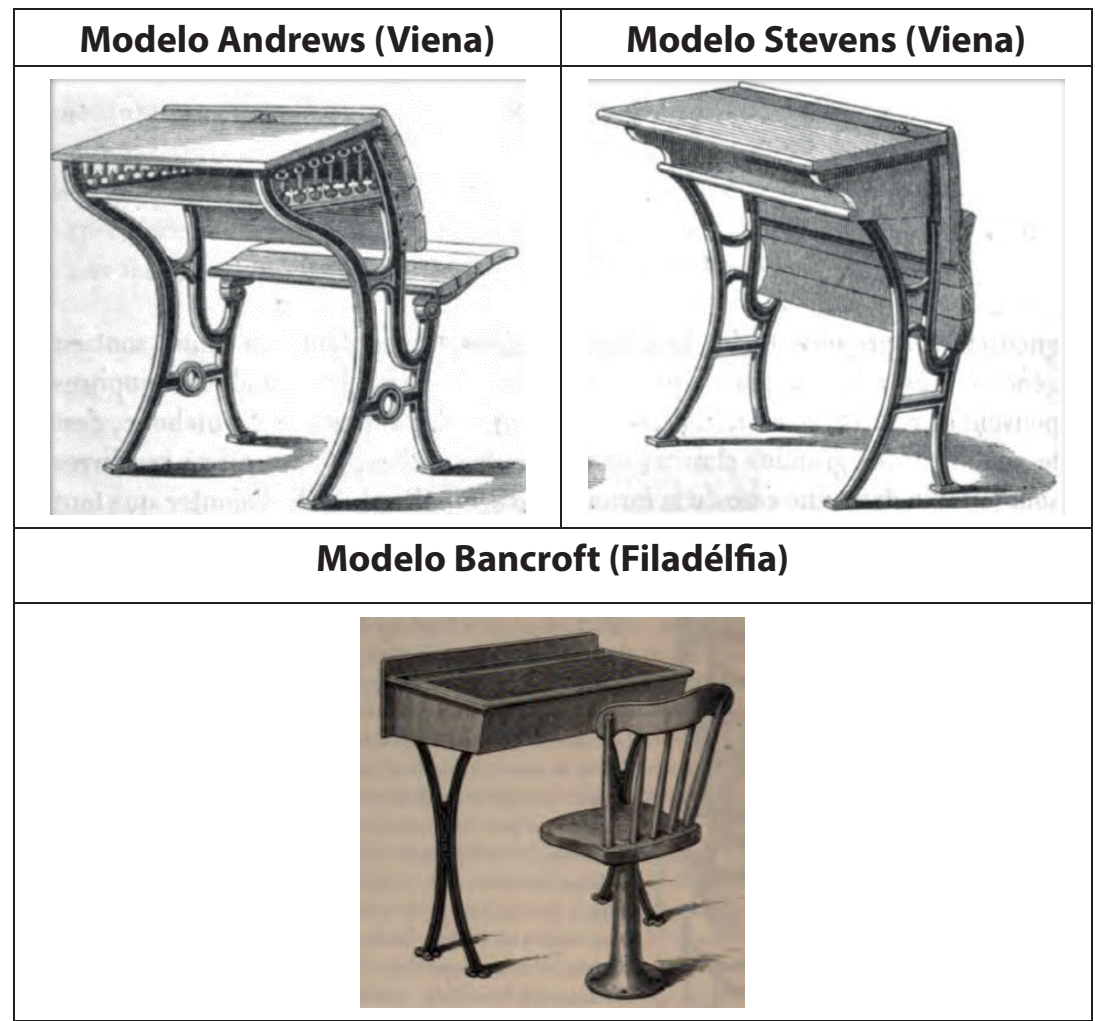

Fonte: Elaborado pelos autores, a partir de Buisson $(1875,1878)$.

\section{Considerações finais}

O desenvolvimento industrial oitocentista foi fundamental para a construção de tecnologias consideradas pioneiras e para seu êxito no mercado escolar. Neste movimento é possível identificar investimentos e iniciativas no sentido de produzir artefatos afinados com as recomendações difundidas em eventos internacionais, em impressos pedagógicos e comerciais (RUGONI DE SOUSA, 2019). Vale lembrar que para se chegar a estas páginas tais ideias e recomendações passam por balizas que configuram jogos de forças entre saberes, conformações econômicas e disputas políticas.

Compreende-se que tomar o mobiliário escolar e, mais precisamente, a carteira, como objetos de estudo tem permitido realizar refle- 
xões sobre movimentos e ideias que estiveram envolvidas na constituição e consolidação de projetos para a escolarização primária. Um dos desafios encontrados nessa empreitada tem sido o de superar análises que se concentram em identificar a emergência de alterações das características materiais, e compreender como mudanças observadas se articulam a pensamentos e interesses envolvidos em diferentes âmbitos, como a formação dos Estados nacionais, a transnacionalização das ideias pedagógicas, o circuito das Exposições Universais e a ascensão industrial, por exemplo, os quais contribuíram para a (re)invenção de sentidos e significados atribuídos ao mobiliário escolar.

Desse modo, conforme foi possível observar por meio das análises dos artefatos presentes em diferentes relatórios de Exposições Universais e catálogos de indústrias, há um efeito de transbordamento para outras fábricas no que se refere a tecnologias empregadas na construção dos móveis escolares. Mesmo com algumas diferenças, as imagens nos trazem indícios de um padrão de exigências que se mantém e que é apropriado, reinventado e difundido em diferentes regiões e países seja por meio da indústria, seja por meio de uma mão de obra marceneira local. O que percebemos é a elaboração de um conjunto de estratégias que visavam à adequação de escolas primárias frente aos modelos referenciados como ideais para a escolarização da infância. Mesmo em contextos considerados extremamente precários do ponto de vista material, discursos em defesa de princípios higienistas e pedagógicos se fazem presentes.

É importante ressaltar que os movimentos de provisão material escolar não ocorreram em uma perspectiva evolucionista, ou seja, as escolas não partiram de uma situação de precariedade e avançaram para uma suposta modernização de seu aparato educativo de forma simultânea. Precisamos, ao analisar esses processos, considerar conflitos, movimentos de contradifusão, provenientes de países que não apareciam referendados como exemplos a serem seguidos, bem como interesses e escolhas que envolvem a idealização, fabricação e comercialização dos itens que serviram ao provimento material das escolas e, com o auxílio de diferentes documentos, refletir sobre o lugar que esses artefatos ocuparam (e ocupam) em variados projetos de escolarização. 


\section{Referências}

BOBRICK, G. A. Hygienic requirements of School furniture. Nova lorque, Estados Unidos da América, 1892. 58 f. Disponível em: https:// archive.org/details/hygienicrequirem00bobr/mode/2up. Acesso em: 04 fev. 2020.

BUISSON, F. Dictionnaire de Pédagogie et d'Instruction Primaire. Paris: Librairie Hachette et Cie., 1888. Parte I, Tomo II.

BUISSON, F. Nouveau Dictionnaire de Pédagogie et $d^{\prime}$ 'Instruction Primaire. Paris: Librairie Hachette et Cie., 1911 a. Parte I, Tomo I.

BUISSON, F. Nouveau Dictionnaire de Pédagogie et $d^{\prime}$ 'Instruction Primaire. Paris: Librairie Hachette et Cie., 1911 b. Parte I, Tomo II.

BUISSON, F. Rapport sur L'Instruction Primaire à L'Exposition Universelle de Philadelphie en 1876. Paris, França. Imprimerie Nationale, 1878. 716 f. Disponível em: https://archive.org/details/ rapportsurlinst00natigoog. Acesso em: 04 fev. 2020.

BUISSON, F. Rapport sur L'Instruction Primaire à L'Exposition Universelle de Vienne en 1873. Paris, França. Imprimerie Nationale, 1875. 378 f. Disponível em: Biblioteca Nacional da França.

CAMPAGNE, É. M. Diccionario Universal de Educação e Ensino. Trasladado ao Portugues por Camillo Castello Branco e ampliado pelo traductor nos artigos deficientes em assumptos relativos a Portugal. Nova Edição portuguesa illustrada e consideravelmente aumentada com um crescido numero de artigos coordenados dos principaes escriptores de pedagogia por José Nicolau Raposo Botelho. Porto: Livraria Internacional de Ernesto Chardron, v. 1, 1886a.

CAMPAGNE, É. M. Diccionario Universal de Educação e Ensino. Trasladado ao Portugues por Camillo Castello Branco e ampliado pelo traductor nos artigos deficientes em assumptos relativos a Portugal. Nova Edição portuguesa illustrada e consideravelmente aumentada com um crescido numero de artigos coordenados dos principaes escriptores de pedagogia por José Nicolau Raposo Botelho. Porto: Livraria Internacional de Ernesto Chardron, v. 2, 1886b.

GASPAR DA SILVA, V. L.; SOUZA, G. Objetos de utilidade prática para o ensino elementar: museus pedagógicos e escolares em debate. In: 
GASPAR DA SILVA, Vera Lucia; SOUZA, Gizele de; CASTRO, César Augusto (Orgs.). Cultura material escolar em perspectiva histórica: escritas e possibilidades. Vitória: EDUFES, 2018. p. 119-142. (Coleção Horizontes da Pesquisa em História da Educação no Brasil; v. 14).

GEO. M. HAMMER. Illustrated catalogue of School and College Furniture and Educational Apparatus. Londres, Inglaterra, 1893. Disponível em: Centro de Documentación e Investigación - Museo Pedagógico "José Pedro Varela", Montevideo, Uruguai.

HOBSBAWM, E. J. A era do capital: 1848-1875. 13. ed. São Paulo: Paz e Terra, 2007. 459 p.

KUHLMANN JÚNIOR, M. As grandes festas didáticas: a educação brasileira e as exposições internacionais (1862-1922). Bragança Paulista, SP: Editora da Universidade São Francisco, 2001. 262 p.

MANIQUE DA SILVA, C. Modelos de carteiras escolares propostos pela Direção-Geral de Instrução Pública de Portugal (1877): a referência da Exposição Universal de Viena. Educar em Revista, Curitiba, v. 35, n. 76, p. 51-69, ago. 2019. Disponível em: https://revistas.ufpr.br/educar/article/ view/67679. Acesso em: 09 maio 2020.

P. GARCET \& NISIUS. Mobilier scolaire. Matériel d'enseignement. Catalogues. Recueil. Paris, França, 1882. Disponível em: Biblioteca Nacional da França.

PESAVENTO, S. J. Exposiç̧̃es Universais: Espetáculos da Modernidade do Século XIX. São Paulo: Editora Hucitec, 1997.

PRIMEIRA EXPOSIÇÃO PEDAGOGICA. Primeira Exposição Pedagogica do Rio de Janeiro: Documentos. Rio de Janeiro, Typographia Nacional, 1884. Acervo: Biblioteca Pedagógica Central do Departamento de Educação. São Paulo.

RIANT, A. Hygiène Scolaire: influence de l'école sur la santé des enfants. Paris, França. 1874. 280 f. Disponível em: https://archive.org/details/ hyginescolaire00rian. Acesso em: 01 jan.2020.

RODRÍGUEZ, S. B. Higiene Escolar en sus relaciones con la miopia. Imprensa Artistica de Dornaleche y Reyes, Montevideo, Uruguai, 1891. 104 f. Disponível em: https://archive.org/details/9215421.nlm.nih.gov. Acesso em: 01 jan. 2020. 
ROSS. J. L. Ross' Illustrated Catalogue of Improved School, Church, and Vestry Furniture. Boston, Massachusetts, Estado Unidos da América, 1872. Disponível em: internet archive. https://archive.org/ details/illustratedcatal00ross. Acesso em: 04 fev. 2020.

RUGONI DE SOUSA, G. Da indústria à escola: relações da fábrica móveis CIMO com o mercado escolar (1912-1954). 2015. 217 f. Dissertação (Mestrado em Educação) - Universidade do Estado de Santa Catarina, Centro de Ciências Humanas e da Educação, Florianópolis, 2015.

RUGONI DE SOUSA, G. A (re)invenção do mobiliário escolar: entre saberes pedagógicos, higienistas e econômicos (1851-1889). 2019. Tese (Doutorado em Educação), Universidade do Estado de Santa Catarina, Florianópolis, 2019.

SARAZIN, M. Manual das escolas elementares d'ensino mutuo. Obra traduzida por João Portella. Bahia:Typ. de A. O. da França Guerra e Comp. $1854.67 \mathrm{f}$.

THE NATIONAL SCHOOL FURNITURE. Illustrated catalogue of new and improved styles of school and church furniture and school apparatus. Nova lorque, Nova lorque e Chicago, Illinois, Estado Unidos da América. 1872. Disponível em: https://archive.org/details/ new+and+improved+styles+of+school+and+church+furniture+and+ school+apparatus.

VIÑAO FRAGO, A. Higiene, salud y educación en su perspectiva histórica. Educar, Curitiba, n. 36, p. 181 - 213, 2010. Disponível em: http://www. scielo.br/pdf/er/n36/a13n36.pdf. Acesso em: 30 maio 2019.

Recebido em: setembro/2020

Aceito em: setembro/2020 